\title{
O DESENHO INSTITUCIONAL DAS POLÍTICAS INDUSTRIAIS: INCENTIVOS FISCAIS CONCEDIDOS AO SETOR AUTOMOBILÍSTICO E SUAS CONTRAPARTIDAS
}

\author{
THE INSTITUTIONAL DRAFTING OF INDUSTRIAL \\ POLICIES: TAX INCENTIVES GRANTED FOR THE \\ AUTOMOBILE INDUSTRY AND ITS COMPENSATIONS
}

\author{
SIMONE BENTO MARTINS CIRILO ${ }^{1}$ \\ GIOVANI CLARK ${ }^{2}$ \\ LEONARDO ALVES CORRÊA ${ }^{3}$
}

\begin{abstract}
RESUMO: Reconhecendo a permanente adoção de incentivos tributários ao setor automotivo, o trabalho tem objetivo: verificar se o desenho institucional das normas instituidoras dos incentivos fiscais mais relevantes concedidos às empresas do setor automobilístico nos últimos 30 anos foi dotado de contrapartidas aos particulares, pois tais normas premiais devem cumprir os comandos constitucionais. Para tanto, serão analisadas quatro experiências transcorridas nas últimas décadas: (i) os incentivos decorrentes da Câmara Setorial Automotiva implementada entre 1991 e 1992; (ii) o Novo Regime Automotivo, estabelecido entre 1995 e 1999, (iii) o InovarAuto, instituído em 2012, e o (iv) o novo marco regulatório, Rota 2030, instituído no ano de 2018. Além disso, verificaremos alguns benefícios pontuais de redução de tributos, que não fizeram parte dos programas mais extensos citados. A metodologia será eminentemente documental e bibliográfica e o estudo sobre o desenho institucional das normas premais será realizada a partir do referencial teórico da obra do Professor Washington Peluso Albino de Souza.
\end{abstract}

PAlavRas-Chave: Incentivos fiscais; setor automobilístico; contrapartidas aos particulares.

\footnotetext{
${ }^{1}$ Mestra em Direito Público pela Universidade Católica de Minas Gerais. Especialista em Direito Tributário pelo Instituto Brasileiro de Estudos Tributários. Graduada em Direito pela Universidade Federal de Minas Gerais. Advogada. Contato: simonebentomartins@gmail.com.

2 Doutor em Direito Econômico pela UFMG. Professor da graduação e pós-graduação estrito senso da PUC Minas. Docente da graduação da Faculdade de Direito da UFMG. Contato: giovaniclark@gmail.com.

${ }^{3}$ Doutor em Direito Público pela PUC Minas. Professor dos Cursos de graduação e pós-graduação em Direito da Universidade Federal de Juiz de Fora. Contato: leoalvescorrea@gmail.com.
} 
AbStRACT: Recognizing the permanent adoption of tax incentives to the automotive sector, the aim of this study is to verify if the most relevant tax incentive rules granted to companies in the last 30 years prescribe any individuals compensation, according to constitutional commands. In order to do so, we will analyze four experiences that have occurred in the last decades: (i) the incentives derived from the Automotive Sectorial Chamber implemented between 1991 and 1992; (ii) the New Automotive Regime, established between 1995 and 1999, (iii) Inovar-Auto, established in 2012, and (iv) the new regulatory framework, Rota 2030, established in 2018. In addition, we will verify some punctual benefits, which were not part of the larger programs cited. The study of Professor Washington Peluso Albino de Souza will be our theoretical reference and the research will be eminently documentary and bibliographical.

KEYWORDS: Tax incentives; Automotive sector; Individual compensations.

\section{INTRODUÇÃO}

A indústria automotiva representa um importante setor da economia industrial, sendo que no Brasil - um país marcado pela forte especialização em bens primários, em particular, as commodities agrícolas - o setor simboliza uma tentativa de coordenação entre o Estado e o mercado na busca por uma estrutura produtiva com maior complexidade e sofisticação tecnológica.

Nos últimos 30 anos da política econômica brasileira, independentemente da orientação ideológica dos governantes, o setor automotivo segue sempre como titular de benefícios de regimes especiais de tributação e de diferentes formas de estímulos, não experimentados por outros setores da economia. Trata-se de um de típico caso de política industrial na qual um setor econômico é identificado como estratégico para fins do desenvolvimento nacional e, portanto, passa a usufruir de um regime jurídico próprio no âmbito do exercício de suas atividades econômicas. No âmbito regulatório, a União institui as normas premiais, por meio das quais concede incentivos visando à indução dos comportamentos dos agentes econômicos, uma consequência regulatória positiva induzindo as decisões privadas.

No início dos anos 1990, a partir de uma orientação política do governo em promover a competitividade e aumentar a concorrência, o governo federal criou a câmara setorial tripartite, composto por representantes da União, empresários e empregados com o objetivo de viabilizar medidas de proteção ao setor automotivo. Anos mais tarde, após a implementação do Plano Real, a União, não obstante a sua tônica liberal, novamente favoreceu o setor automotivo, desta vez com um regime especial de tributação - Novo Regime Automotivo. Em 2004, a política industrial foi restabelecida como agenda estatal, sendo que o alvo de suas medidas voltava- 
se para a promoção da inovação em segmentos tidos como inovadores futuro. Com o passar dos anos, a lógica anterior se repetiu com o Inovar-Auto, um novo regime especial de tributação para o setor automotivo foi incluído nas novas versões da política industrial. E, por fim, em 2018, foi instituído com o Rota 2030 um novo marco regulatório para o setor, sob a justificativa de garantir estabilidade e previsibilidade no desenvolvimento de novos produtos.

Além dos referidos programas, nos últimos anos foram destinados ao setor outros inúmeros incentivos fiscais, como, por exemplo, a redução do Imposto de Importação na aquisição de bens provenientes do exterior para o segmento, combinando proteção de mercado para os veículos manufaturados nacionalmente, com facilidades para a importação de seus insumos industriais; além da redução do Imposto sobre Produtos Industrializados, em 2008 e 2012, notadamente em períodos de crise mundial.

Reconhecendo a permanente adoção de incentivos tributários ao setor automotivo, este trabalho tem dois objetivos: (i) verificar se as normas instituidoras dos incentivos fiscais mais relevantes concedidos às empresas do setor automobilístico nos últimos 30 anos foram dotadas de contrapartidas aos particulares; (ii) investigar se a instituição dessas normas premiais cumpriu ou não o objetivo da Constituição Econômica de 1988, na medida em que a destinação dos investimentos públicos deve ter como função efetivar o programa constitucional.

Nesse sentido serão analisadas quatro experiências transcorridas nas últimas décadas: (i) os incentivos decorrentes da Câmara Setorial Automotiva implementada entre 1991 e 1992; (ii) o Novo Regime Automotivo, estabelecido entre 1995 e 1999 (Medida Provisória noo 1.024/95, seua reedições e a Lei no 9.449/97), (iii) o Inovar-Auto, instituído em 2012 (Medida Provisória no 563/2012, posteriormente convertida na Lei no $12.715 / 2012$ ), e o (iv) o novo marco regulatório, Rota 2030, instituído no ano de 2018 (Medida Provisória nº 843/2018, posteriormente convertida na Lei $\mathrm{n}^{\mathrm{o}}$ 13.755/2018). Além disso, verificaremos alguns benefícios pontuais de redução de tributos, que não fizeram parte dos programas mais extensos. Iremos avaliar os acordos e as leis federais instituidoras dos referidos regimes especiais de tributação, com o objetivo de verificar se as suas normas instituidoras foram dotadas de contrapartidas aos particulares, pois tais normas premiais devem cumprir os comandos constitucionais.

Partindo do referencial teórico de que as normas que concedem incentivos fiscais possuem a característica de premiais, típicas do Direito Econômico Brasileiro, iremos estudar, com base nos ensinamentos do Professor Washington Peluso Albino de Souza, de que forma essas atendem aos ditames da Constituição Econômica. É o que se passar a demonstrar na seção seguinte, por meio de pesquisa eminentemente documental e bibliográfica. 


\title{
II. Normas Premiais E A CONSTITUIÇÃo Econômica
}

Ao destrinchar a definição de Direito Econômico, o Professor Washington Peluso Albino de Souza (2017, p. 23-30) ensina que tal ramo do Direito tem por objeto o tratamento jurídico da política econômica e, como tal, é constituído pelo conjunto de normas de conteúdo econômico que assegura a defesa e harmonia dos interesses individuais e coletivos, de acordo com a ideologia definida pela Constituição vigente. Sobre a ideologia da Constituição, Souza (2017, p. 28-29) esclarece:

\begin{abstract}
Não se trata do sentido filosófico ou político amplo, de ideologia, nem mesmo de cada ideologia política geralmente referida, tal como a capitalista, a socialista, a comunista, etc. Independentemente dessa configuração, referimo-nos aos princípios que sejam fundamentais na ordem jurídica considerada, mesmo que isoladamente se identifiquem com alguma daquelas ideologias políticas acima referidas.

A ideologia a que nos referimos é aquela definida, em Direito Positivo, no estado de Direito, pela Constituição Vigente, em cada época e em cada país. Por isso, a definimos como ideologia constitucionalmente adotada. Fica estabelecida, pois, a diferença entre esta e a que se possa entender por ideologia dos modelos teóricos tradicionais, ou seja, conjunto de ideias, de princípios ou de teorias destinados a explicar, abstratamente, a organização social, a estrutura política e assim por diante.
\end{abstract}

Dentre as normas de conteúdo econômico destacam-se as normas premiais, aplicadas aos estímulos e incentivos, com o objetivo de induzir o comportamento dos agentes. Nesses casos, a sanção prevista no consequente da norma é premial, isto é, as normas se fundamentam numa consequência positiva em razão da prática de uma conduta desejável pelo Estado, com o objetivo de concretizar os comandos constitucionais.

As normas premiais representam uma modalidade de ação do Estado sobre o domínio econômico, sendo classificada como uma intervenção orientadora, como ensina Clark (2001, p. 31):

De acordo com a política econômica optada, a intervenção pode ser orientadora, dirigida, combinada, contratual. $\mathrm{Na}$ intervenção orientadora, o Estado intervém na economia orientando os agentes privados para atuarem de determinada forma, no intuito de alcançarem determinados objetivos. Não existe nesse tipo de ação econômica estatal qualquer espécie de comando normativo coator 
ou proibitivo, mas, ao contrário, incitações e seduções ao particular para agir de determinada maneira, oferecendo prêmios, concessões de imóveis, isenções e incentivos tributários, avais etc.

E para que as normas premiais cumpram a sua função dentro do Direito Econômico, assegurando a harmonia dos interesses individuais e coletivos, devem se conformar à ordem jurídica-política-econômica vigente, corporificada pela ideologia da Constituição Econômica (artigos 170 a 192 da Constituição Federal de 1988 - núcleo central da Ordem Econômica Constitucional). No caso brasileiro, tal ideologia tem sido definida constitucionalmente com ênfase no desenvolvimento, na valorização do trabalho humano, na livre iniciativa e na justiça social, ou seja, trata-se de uma ideologia plural, mesclando comandos normativos complexos e diretivos de opções/visões políticas e econômicas distintas.

Em termos gerais, "ideologia constitucionalmente adotada" referese ao processo jurídico-político de conversão de "ideologias econômicas puras" (capitalismo, nacionalismo, socialismo) em uma ordem juridicamente positivada mesclando-as em um único texto a ser aplicado. Trata-se de um mecanismo de juridificação do discurso ideológico construído, no plano econômico-político, pelo Poder Constituinte. Em última análise, a constitucionalização de fatos econômicos significa uma alteração do tipo de "ordem", isto é, a transmutação de institutos do sistema econômico - e por isso aberto a quaisquer ideologias - para uma ordem jurídicoeconômica (CLARK; CORRÊA; NASCIMENTO, 2013, p. 276)

$\mathrm{Na}$ concepção da ordem jurídica-política-econômica encontram-se os dados essenciais à ideia de justiça econômica, que foca cada elemento da realidade econômica de acordo com o princípio jurídico da responsabilidade pelos atos praticados, ao mesmo tempo em que toma por contingente ideológico, não o interesse privado ou o interesse coletivo, cada um deles isoladamente, mas ambos inseridos no objetivo mais amplo da Justiça Social:

O enunciado justiça social poderia dar margem a discussões, visto como deixa entrever a falta de clareza e de unanimidade de conceito. Mas subentende, por certo, o interesse social acima do particular, se tomamos o pensamento clássico. No entanto, o texto constitucional consagra o princípio neoliberal, por exemplo, o equilíbrio entre o particular e o coletivo, por certo dirigindo aquele 
no sentido de melhor atender esse último, temos a Regra do Direito Econômico, que assim apresentamos:

O Direito econômico toma o interesse social como fundamento dos seus 'juízos de valor' e por essa orientação procura realizar os princípios da Justiça Distributiva. (SOUZA, 2017, p.126)

As premissas de responsabilidade pelos atos praticados e o equilíbrio de interesses para alcance da justiça social também devem ser observadas no relacionamento do Estado com particulares. E, com o "entrosamento cada vez maior entre ambos, as suas relações enveredam-se pelo campo de obrigações mútuas, abrindo uma nova área que não se confunde com as relações de 'dominação' ou 'autoritarismo'”' (SOUZA, 2017, p. 188).

Aplicando-se o entendimento ao presente estudo, conclui-se que, para que os incentivos e benefícios fiscais concedidos pelo Estado às empresas do ramo automotivo, por meio de normas premiais, se adequem à ordem jurídica-políticaeconômica vigente, é necessário o estabelecimento de obrigações também aos particulares. Ou seja, o Estado concede um determinado incentivo ao particular que, em contrapartida, deve adotar algum procedimento de forma a alcançar ou, pelo menos, fomentar a justiça social, valor que compõe a ideologia constitucional, sempre visando materializar os comandos da Constituição voltados ao pleno emprego (art. 170, inciso VIII, da CR/88), da defesa ao consumidor (art. 170, V, $\mathrm{CR} / 88$, da soberania nacional (art. 170, I, da CR/88), da defesa do meio ambiente (art. 170, VI, da CR/88), do desenvolvimento tecnológico (art. 218 da CR/88) 4

Considerando que a concessão de incentivos e benefícios fiscais representam uma queda na arrecadação de receitas públicas, a análise de sua adequação aos comandos constitucionais se faz ainda mais relevante pelo fato de, na ordem jurídica e social de um Estado Democrático de Direito, como é o Brasil, o tributo

deve ser visto como um instrumento de transformação social necessário para conferir e preservar a legitimidade do regime político e dar eficácia aos direitos constitucionais dos cidadãos, e não como um capricho dos governantes que simplesmente retira recursos da atividade produtiva para desbaratá-los nas gargantas vorazes da máquina estatal. (GODOI, 2017).

Assim sendo, passemos a analisar os incentivos tributários mais relevantes concedidos pelo Estado nas últimas décadas e a sua adequação com a ordem jurídica-política-econômica brasileira.

\footnotetext{
4 Sobre os comandos constitucionais, Grau (2016).
} 


\section{CÂmara Setorial do Complexo Automotivo}

As câmaras setoriais surgiram no final dos anos 80, objetivando estabelecer diagnósticos de competitividade setorial, identificar as causas das distorções existentes e indicar as estratégias voltadas para objetivos de política industrial.

CLARK (2001, p. 32) esclarece que a criação das Câmaras setoriais seria uma forma de intervenção estatal combinada, em que

o Estado, juntamente com os particulares - sejam empresários, trabalhadores, consumidores, profissionais liberais, ambientalistas - por intermédio de suas entidades representativas, trocam informações e dados econômicos, estabelecem metas, objetivos, comportamentos conjuntos ou individuais, bem como estabelecem/executam as medidas políticas econômicas.

(...)

No Brasil, através de conselhos ou câmaras setoriais, presenciamos a intervenção combinada, principalmente setorial.

A Lei n⿳o 8.178, de 1o de março de 1991, editada pelo Presidente Fernando Collor de Mello para estabelecer regras sobre preços e salários, determinava, em seu artigo $23^{5}$, que no prazo de 30 dias deveriam ser constituídas câmaras setoriais destinadas a analisar a estrutura de custos e preços em setores e cadeias produtivas específicas, com o objetivo de assessorar o ministro da Economia, Fazenda e Planejamento no monitoramento da flexibilização dos preços, congelados a partir daquela data. $\mathrm{O}$ ministro definiria as competências e abrangência das câmaras e designaria, por portaria, os seus membros, que seriam representantes do Ministério da Economia, Fazenda e Planejamento (MEFP), dos empregadores dos respectivos setores produtivos, e dos trabalhadores dos respectivos setores produtivos ou das entidades sindicais nacionais.

Após a regulamentação pelas Portarias MEFP no 463/1991 e 762/1991, o escopo das câmaras setoriais foi ampliado, passando a tratar de outros assuntos, além da negociação dos preços, como questões estruturais de longo e médio prazos, visando

\footnotetext{
${ }^{5}$ Art. 23. Serão constituídas, no prazo de trinta dias, câmaras setoriais destinadas a analisar a estrutura de custos e preços em setores e cadeias produtivas específicas para assessorar o Ministro da Economia, Fazenda e Planejamento no monitoramento da flexibilização de preços. $\S 1^{\circ}$ As competências e a abrangência das câmaras setoriais serão definidas pelo Ministro da Economia, Fazenda e Planejamento. $\S 2^{\circ}$ As câmaras serão compostas por membros designados por portaria do Ministro da Economia, Fazenda e Planejamento, representantes: a) do Ministério da Economia, Fazenda e Planejamento; b) dos empregadores dos respectivos setores produtivos; c) dos trabalhadores dos respectivos setores produtivos ou das entidades sindicais nacionais.
} 
formular e implementar a política de competitividade industrial (ANDERSON, 1999).

Em março de 1992, após três meses de negociações, a câmara setorial do complexo automotivo estabelece um acordo, sendo a experiência mais notória das câmaras tripartites, tanto pela importância do seguimento, como por causa da participação efetiva e determinante do Sindicato dos Metalúrgicos do ABC nas negociações. Previsto inicialmente para durar 90 dias, o acordo foi estendido até 31 de dezembro de 1992.

Os acordos firmados no âmbito das Câmaras Setoriais representam uma evolução da intervenção estatal combinada para a contratual, em que, posteriormente à combinação, particulares e Estado celebram acordos e contratos para a sua concretização. Segundo CLARK (2001, p. 32):

Nesse caso, os particulares, juntamente com o Estado, atuam de forma direcionada para alcançarem os objetivos da intervenção animados por um pacto que oferece aos primeiros, vantagens fiscais, subvenções, crédito, facilidades de transações internacionais, obtendo o segundo a realização de políticas voltadas ao bem-estar social.

É importante destacar que, no fim dos anos 80 e início dos anos 90, o setor automotivo experimentava em grande declínio na venda de automóveis, reduzindo de forma significativa a participação do setor no PIB brasileiro (ANFAVEA, 2019), inclusive devido a pressões inflacionárias. E esse cenário afetava diretamente $\mathrm{o}$ lucro das montadoras de veículos e das empresas de autopeças, bem como a oferta de emprego no setor e a própria arrecadação tributária.

Para cumprir o objetivo de recuperação do setor automotivo, todos os grupos envolvidos cederam parcela de seus interesses. O principal acordo era o de uma redução de $22 \%$ do preço dos automóveis, a fim de alavancar as vendas, o que seria obtido por uma partilha tripartite de responsabilidades (ANDERSON, 1999, p. 1722). Ao Governo coube as seguintes medidas: (i) redução de $12 \%$ na carga tributária (sendo $6 \%$ de IPI e a sugestão ao Confaz para redução de $6 \%$ de ICMS); (ii) a edição de nova regulação, pelo Banco Central, que permitisse a reabertura dos consórcios; (iii) a definição de um programa de financiamento para automóveis e caminhões por meio dos bancos públicos, e (iv) a definição de um projeto de lei com incentivos para exportação. Os empresários assumiram o compromisso de reduzir a sua margem de lucro, sendo que $4,5 \%$ da redução seria devido às montadoras e 3\%, aos fornecedores de autopeças. Além disso, o setor empresarial comprometeu-se com uma política de correção dos salários e de manutenção do nível de emprego até junho de 1992, posteriormente estendido até julho de 1993. Os empregados, por sua vez, aceitaram os termos da política salarial e prorrogaram a data-base da categoria (inicialmente seria em $1^{\underline{0}}$ de abril, passando para $1^{\circ}$ de julho). 
Em fevereiro de 1993, já no governo do Presidente Itamar Franco, foi firmado um segundo acordo no âmbito da Câmara Automotiva, seguindo a linha da partilha de encargos. Dessa vez, além do compromisso de redução de preços dos veículos, em adicionais $10 \%$, foram estabelecidas outras metas relacionadas à quantidade de veículos a serem vendidos nos anos seguintes e o montante de investimentos por parte dos empresários (ANDERSON, 1999, p. 17-22). Entre outras medidas adotadas, tivemos o aumento do prazo dos consórcios e a ampliação dos financiamentos via BNDES (Banco Nacional de Desenvolvimento Econômico e Social); os incentivos tributários, tendo a União concedido uma nova redução de IPI, de $6 \%$ para automóveis e de $2 \%$ para veículos comerciais leves, e se comprometido ainda a propor ao CONFAZ (Conselho Nacional da política Fazendária) as seguintes reduções de ICMS: de $12 \%$ para $9 \%$ para veículos com menos de mil cilindradas; de $12 \%$ para $7 \%$ para os caminhões; e de $8,8 \%$ para $7 \%$ para os tratores e máquinas agrícolas. Já os empresários, encarregados de promover os investimentos, assumiram o compromisso de realizar novas reduções nas margens de lucro e os trabalhadores acataram a política salarial, baseada em um escalonamento dos aumentos reais de salário, que seria diferido entre os três anos subsequentes.

Anderson (1999, p. 20) destaca em sua pesquisa que em março de 1993, foi assinado pela Presidência da República e pelas montadoras um protocolo de intenções prevendo a fabricação de modelos de 1.000 cilindradas, os carros populares e alguns outros modelos de 1.600 cilindradas, com uma alíquota de $0,1 \%$ de IPI. Tal acordo foi diferente dos anteriores, pois teve como único ponto comum com os primeiros o fato de ter como estímulo básico a redução tributária, já que não foi exigida qualquer contrapartida por parte dos empresários, a não ser o compromisso de manter o preço do veículo abaixo do nível simbólico de 7 mil dólares, o que não chegou a ocorrer na prática. Além disso, diferentemente do ocorrido nos acordos anteriores, o Protocolo foi costurado nos bastidores, sem a participação dos demais interessados, como os trabalhadores, as demais esferas do governo e do restante do setor privado. Esqueceu-se da democracia participativa na elaboração da política setorial.

A partir de então, a câmara setorial foi paulatinamente deixando de ser encarada como um fórum de negociações, sendo definitivamente encerrada com a vigência da governança econômica do Plano Real, quando a União centralizou as decisões econômicas no Ministério da Fazenda e deixou de recorrer às câmaras para a tomada de decisões referentes às políticas econômicas setoriais.

Podemos constatar pela análise acima é que o desenho institucional do primeiro e segundo acordos da Câmaras Setoriais Automotivas foram forjados em um ambiente onde os incentivos fiscais pressupunham que os particulares, empresários e empregados, fornecessem contrapartidas á sociedade, abrindo mão 
de parcelas de seus interesses (para os primeiros, margem de lucro e para os segundos, reajuste salarial), por um objetivo de comum de recuperação da indústria automobilística brasileira.

A exceção desse "regime" vigente no início dos anos 90 se deu com o protocolo de intenções firmado entre a União e as montadoras de veículos em 1993, à margem das Câmaras Setoriais, que não previram qualquer obrigação concreta a ser cumprida pelos empresários em troca da redução à $0,1 \%$ do IPI para veículos populares, na medida em que a suposta redução do preço do veículo não pode ser considerada como contrapartida.

Apesar de não ter vingado, provavelmente pela falta da tradição brasileira no planejamento de metas de longo prazo e de compromissos firmados de forma aberta para todos os agentes, o debate que foi estabelecido entre a União e os particulares, no âmbito das câmaras setoriais, deve ser considerado tão importante quanto os resultados concretos das negociações. E, pelo menos no que tange às metas de aumento do número de veículos vendidos, essas foram alcançadas (ANDERSON, 1999) ${ }^{6}$, fazendo com que o setor automobilístico recuperasse o fôlego.

Após esse período, acompanhada da abertura comercial promovida pela política econômica do Plano Real, não se verificou uma nova política industrial efetiva na época, deixando o setor à livre regulação do mercado, acarretando uma nova queda na competitividade. E então, em 1995, já no governo do Presidente Fernando Henrique foi editada a Medida Provisória no 1.024/94, reeditada por diversas vezes para, posteriormente, ser convertida na Lei no 9.449/97, instituindo o Novo Regime Automotivo.

\section{Novo Regime Automotivo}

Apesar de sua tônica neoliberal reguladora (CLARK, 2006), o governo do Presidente Fernando Henrique, a partir de 1995, com a edição da Medida Provisória no 1.024/95, voltou a apresentar um conjunto de medidas tributárias para promover o setor automotivo. À época, em razão do Plano Real, o Brasil experimentava uma relativa estabilidade econômica, com inflação anual de apenas um dígito percentual.

Em análise à Medida Provisória e às suas reedições, bem como à Lei no 9.449/97, verifica-se a autorização para que o Poder Executivo conceda incentivos fiscais relacionados à importação, com vigência até 31 de dezembro de 1999, para as empresas montadoras e fabricantes de veículos automotores de passageiros e de caminhões.

Dentre os incentivos inicialmente concedidos destaca-se a redução para $2 \%$ da alíquota do imposto de importação sobre máquinas, equipamentos novos, bem como os respectivos acessórios, sobressalentes e peças de reposição, matérias-

\footnotetext{
${ }^{6}$ Vide ANFAVEA (2019).
} 
primas, partes, peças, componentes. Após, com as reedições da MP, os incentivos foram sendo majorados, com o aumento das reduções da alíquota do imposto de importação para determinados tipos de bens.

Em contrapartida, as empresas que aderissem ao Novo Regime Automotivo teriam que garantir um índice de nacionalização na produção dos veículos de, pelo menos, $60 \%$, sendo que se considerariam, para efeitos do índice de nacionalização, as peças produzidas no Brasil ou na Argentina. ${ }^{7}$ Além disso, a partir de 1998, foi instituída uma nova contrapartida relacionada à vinculação entre os benefícios de importação e as metas de exportação: originalmente, para cada US\$ 1 despendido com a importação, a empresa deveria exportar US\$1,5 (Decreto no 2.179/1997).

Diferentemente do que se verificou com as Câmaras Setoriais, em que havia uma prévia e longa negociação das medidas a serem adotadas pelo setor, com um baixo índice de contestação posterior, a instituição do Novo Regime Automotivo se deu de uma forma centralizada na União (autoridades e técnicos), sendo submetida ao controle de duas entidades: uma internacional, e um interna.

A Organização Mundial do Comércio, em função de denúncias do Estados Unidos e do Japão, entendeu que a política brasileira violava o tratado de livre comércio ao dar tratamento privilegiado para indústrias nacionais ou para produtos de origem local, levando o Brasil a fechar acordos com tais nações, além da Coreia do Sul e União Europeia, flexibilizando os incentivos para a exportação de montadoras neles localizadas e se comprometendo a importar veículos provenientes daquelas localidades.

E o Congresso Nacional quando, na negociação para aprovação da Medida Provisória que estabelecia o Novo Regime Automotivo, pactuou com o Executivo federal a definição de incentivos para o desenvolvimento regional, criando um Regime Especial para as montadoras instaladas, ou que viessem a se instalar, nas Regiões Norte, Nordeste e Centro-Oeste do Brasil.

Esse Regime Especial foi instituído via novos custos fiscais. A Medida Provisória no 1.532/97, posteriormente convertida na Lei no 9.440/97, além das reduções do imposto de importação já previstas a todas as montadoras do setor, previu: a (i) redução de 50\% do IPI incidente na aquisição de máquinas, equipamentos novos, importados ou de fabricação nacional, bem como os respectivos acessórios, sobressalentes e peças de reposição; (ii) redução de $45 \%$ do IPI incidente na aquisição de matérias-primas, partes, peças; (iii) isenção do adicional ao frete para renovação da Marinha Mercante - AFRMM; (iv) isenção do IOF nas operações de câmbio realizadas para pagamento dos bens importados; (v) isenção do imposto sobre a renda e adicionais, calculados com base no lucro da exploração do

\footnotetext{
${ }^{7}$ Shapito (2017, p. 444-446) detalha sobre o Regime Automotivo da Argentina e sua relação com a política industrial brasileira.
} 
empreendimento; $\mathrm{e}(\mathrm{v})$ concessão de crédito presumido do imposto sobre produtos industrializados, como ressarcimento do PIS e da COFINS, no valor correspondente ao dobro das referidas contribuições que incidiram sobre o faturamento das montadoras de veículos localizadas nas regiões Norte, Nordeste, Centro-Oeste.

Também na referida lei foram instituídas as contrapartidas relacionadas à garantia do índice de nacionalização das autopeças utilizadas para a fabricação dos veículos, e ao cumprimento das metas de exportação.

Verifica-se, portanto, que apesar da forma unilateral em que foi instituído o Regime Automotivo, e os altos custos fiscais decorrentes das contestações posteriores, fato é que houve a previsão de contrapartidas a serem cumpridas pelos empresários, de forma a favorecer a indústria nacional.

Todavia, mais uma vez, em razão da falta de um planejamento a longo prazo, a política econômica fixada com o Regime Automotivo não se sustentou e, como observa, Shapiro (2017, p. 447-448), na década de 2000, o setor voltou a enfrentar problemas de competitividade, com o desequilíbrio da balança comercial, observando-se, depois de um período positivo - até 2005, período em que as importações de veículos passaram a superar as exportações. Nesse contexto, no ano de 2011, foi editado o Plano Brasil Maior (Lei no 12.546/2011), a nova versão da política industrial brasileira instituindo o Inovar-Auto.

\section{O Programa InOVAR-Auto}

O Programa de Incentivo à Inovação Tecnológica e Adensamento da Cadeia Produtiva de Veículos Automotores - Inovar-Auto foi mais um regime tributário especial concedido pela União por meio da Medida Provisória n ${ }^{0}$ 563/2012, posteriormente convertida na Lei $\mathrm{n}^{\mathrm{o}} 12.715 / 2012$, e regulamentado pelo Decreto $\mathrm{n}^{\mathrm{o}}$ 7.819/2012, com duração prevista até 31 de dezembro de 2017.

A exposição de motivos da Medida Provisória (BRASIL, 2012) contextualiza o cenário econômico de criação do Programa, destacando que, apesar do aumento da venda de veículos novos no âmbito interno, demonstrado pelos elevados níveis de produção e aumento expressivo do número de licenciamentos, vinham sendo observados déficits crescentes na balança comercial do setor e perda de competitividade internacional. Diante do cenário, o Programa foi criado com os objetivos estratégicos de: (i) atrair novos investimentos para o país, a fim de garantir maior nacionalização da produção dos veículos adquiridos pelos consumidores brasileiros, o que tenderia a impactar positivamente a indústria de autopeças; e (ii) fomentar um padrão de produção similar aos internacionais, orientados para o incremento da eficiência energética dos motores, além de sistemas de segurança, e com isso favorecer uma ampliação das exportações. Vejase trecho da Exposição de Motivos da MP nº 563/2012 (BRASIL, 2012):

44. Diante de todos estes elementos, o grande desafio que se 
apresenta para o setor automobilístico no momento reside na busca contínua pela melhoria da competitividade, aprimorando as tecnologias existentes e incorporando e desenvolvendo novas tecnologias. As medidas em questão buscam ter uma atuação proativa no sentido de conter possíveis consequências de um eventual comprometimento da competitividade brasileira, que poderia culminar com o fechamento de fábricas, redução na produção industrial e perda de postos de trabalho. A medida proposta tem por objetivo fortalecer a indústria automotiva nacional e criar incentivos para que haja melhoria do conteúdo tecnológico dos veículos produzidos no País. A competição mundial nessa indústria se mostra cada dia mais condicionada ao avanço tecnológico e à eficiência produtiva. Vários são os campos onde se esperam avanços nos próximos anos, entre eles a proteção ao meio ambiente, a segurança e a eficiência energética.

45. A experiência internacional de políticas direcionadas à eficiência energética mostra que a introdução de um marco regulatório voltado às emissões veiculares estimulará a capacidade tecnológica das montadoras instaladas no país. A medida promoverá o aumento da eficiência veicular da frota brasileira e permitirá que a indústria automotiva nacional atenda aos atuais padrões de produção da indústria automotiva internacional. Além disso, os níveis atuais de eficiência energética de veículos produzidos no Brasil chegam a ser até $40 \%$ menores que o de veículos semelhantes comercializados na Europa e nos EUA. Também na área da segurança veicular, não há no Brasil, produção nem desenvolvimento tecnológico de itens como freios antitravamento (ABS) ou air bags, entre outros.

Para o cumprimento dos objetivos acima, a Governo concedeu incentivos fiscais às empresas instaladas no Brasil que fabricam e comercializam veículos, bem como àquelas empresas estrangeiras com projetos aprovados para se instalarem no Brasil, incentivando o investimento externo.

A habilitação no Inovar-Auto e aproveitamento dos benefícios ficou condicionada ao cumprimento de uma série de requisitos pelas empresas, representando a sua contrapartida aos benefícios tributários concedidos, tais como (i) a realização de investimentos em inovação, pesquisa e desenvolvimento (P\&D); (ii) o dispêndio em engenharia, tecnologia industrial e capacitação de fornecedores; e (iii) à adesão das empresas às normas brasileiras de eficiência energética dos motores. 
O incentivo fiscal ficou totalmente vinculado ao cumprimento dos requisitos acima (contrapartidas), na medida que foi representado pela concessão de crédito presumido de IPI com base nos dispêndios realizados no Brasil com pesquisa, desenvolvimento tecnológico, inovação tecnológica, insumos estratégicos, ferramentaria, recolhimentos ao Fundo Nacional de Desenvolvimento Científico e Tecnológico (FNDCT), capacitação de fornecedores e engenharia e tecnologia industrial básica.

O crédito presumido concedido, na prática, representou uma redução do imposto a pagar, pois era utilizado para deduzir do imposto sobre produtos industrializados apurado.

Há, por fim, um incentivo adicional relacionado especificamente a eficiência energética. Para além da regra de eficiência energética mínima, que conjuntamente com as contrapartidas é uma condição de habilitação da empresa para postular a redução de IPI, há a previsão de um desconto adicional deste tributo para empresas que obtiverem uma redução superior nos patamares de emissão de poluentes. Assim, a partir de 2017, as empresas cujos veículos consumissem 15,46\% a menos de combustível seriam beneficiadas com uma redução de $1 \%$ de IPI; e aquelas cujos veículos atingissem uma eficiência energética com consumo $18,84 \%$ menor que a medida de 2013 garantiriam um benefício adicional de $2 \%$ de desconto do imposto. Tais padrões de emissão eram previstos para serem atingidos na União Europeia até o ano de 2015.

Portanto, se verifica que, no novo desenho institucional do marco regulatório da indústria, criado no âmbito do Plano Brasil Maior, a concessão de incentivos fiscais veio acompanhada do cumprimento de obrigação por parte das empresas, caracterizadas pelo investimento em inovações tecnológicas a serem realizadas no Brasil. Todavia, segundo Shapiro (2017, p. 451) o regime careceu de clareza normativa, tornando a sua implementação menos transparente aos agentes de controle, na medida em que as métricas e contrapartidas não foram clarividentes, demandando um trabalho não trivial de certificação e de medição dos investimentos realizados, para fins de garantir uma apuração adequada e assim dar ensejo a obtenção dos créditos tributários.

Provavelmente por esse motivo, pesquisas (SHAPIRO, 2017, p. 451; LIMA, 2016, p. 92-96; MESSA, 2017, p. 370) ${ }^{8}$ relacionadas à efetividade do Programa constataram que os resultados do Inovar-Auto decepcionaram, não alcançando os objetivos inicialmente propostos relativos ao aumento da competitividade do setor e mesmo à eficiência energética.

Diante dos fracos resultados, a renovação do Programa, encerrado em 31 de dezembro de 2017, sequer chegou a ser cogitada. E, como tal setor da industrial é influente na política econômica, em 2018, ao final do Presidente Michel Temer, passou a vigorar um novo marco regulatório, o Rota 2030, que prevê a concessão

\footnotetext{
8 Vide ainda Carneiro (2017), Sem autor (2017) e Riato (2017).
} 
de incentivos fiscais com o mesmo objetivo de fomentar a inovação por meio da pesquisa e desenvolvimento (P\&D), bem como a continuação da melhoria da sustentabilidade veicular, do consumo de combustível e da valorização dos biocombustíveis, a evolução da segurança veicular e o aumento da competitividade da indústria automobilística brasileira.

\section{O Programa Rota 2030 Mobilidade e Logística}

O Programa Rota 2030 Mobilidade e Logística, com início da vigência em 1ํㅡㄹ de janeiro de 2019, foi instituído por meio da Medida Provisória no 843/2018, posteriormente convertida na Lei $\mathrm{n}^{\mathrm{o}}$ 13.755/2018, publicada em 11 de dezembro de 2018. O Programa foi bastante festejado pela indústria automobilística, tendo sido considerada a política econômica mais promissora do setor no Brasil desde o seu início em 1956.

A Exposição de Motivos da referida Medida Provisória (BRASIL, 2018) deixa claro o seu objetivo de aumento da competitividade do setor, mediante a ampliação da inserção global da indústria automotiva brasileira, por meio da exportação de veículos e autopeças, no contexto em que o setor automotivo mundial sinaliza profundas transformações nos próprios veículos e na forma de usá-los, além da forma de os produzir, em função dos princípios da sustentabilidade ambiental (arts. 170, VI, e 255 da CR/88).

O Programa foi estruturado como política pública de longo prazo, de quinze anos divididos em três ciclos quinquenais, e abrange toda a cadeia de produção e comercialização de veículos, permitindo a habilitação no regime para as montadoras e comercializadoras, as fabricantes de autopeças, além de empresas que tenham projetos de desenvolvimento e produção tecnológica aprovado para fabricação, no País, de novos veículos ou novos modelos, ou de novas soluções estratégicas de mobilidade e logística, e de veículos com tecnologias de propulsão alternativas à combustão.

A meta proposta é a de que, a partir de $1^{0}$ de janeiro de 2019, ocorra um movimento de inserção global progressivo, permitindo que ao final da vigência do programa, a indústria automobilística nacional esteja inteiramente inserida no estado da arte da produção global de veículos automotores. Para tanto, as políticas de estímulo passam pelo fomento da pesquisa e desenvolvimento (P\&D) na área de tecnologia, especialmente em eficiência energética e desempenho estrutural, além das tecnologias assistivas à direção.

O Programa contempla um leque ainda maior de incentivos fiscais se em comparação com os regimes especiais anteriores, pelo fato de abarcar benefícios em quatro tipos de tributo: Imposto sobre a Renda da Pessoa Jurídica (IRPJ) e da Contribuição Social sobre o Lucro Líquido (CSLL), Imposto sobre Produtos Industrializados (IPI), e Imposto de Importação (II). Por se tratar de um programa 
estruturante, os benefícios tributários não miram em uma redução no valor dos veículos para alavancagem de vendas, mas no real investimento na modernização do setor.

As contrapartidas previstas na legislação para que as empresas façam jus aos incentivos fiscais, da mesma forma que no Inovar-Auto, vêm na forma de requisitos para habilitação no Programa. Nesse caso, as contrapartidas se relacionam ao cumprimento de métricas estabelecidos pelo Poder Executivo, por meio do Decreto $\mathrm{n}^{\mathrm{o}}$ 9.557/18, em relação à rotulagem veicular, eficiência energética veicular, desempenho estrutural associado a tecnologias assistivas à direção, dispêndios com pesquisa e desenvolvimento tecnológico.

As métricas estabelecidas no decreto regulador em relação às exigências a serem observadas pelas Empresas na obtenção dos incentivos fiscais são bastante precisas e detalhadas, e o seu cumprimento será monitorado segundo critérios a serem definidos pelo Grupo de Acompanhamento do Programa Rota 2030, composto por representantes do Ministério da Economia e do Ministério da Ciência, Tecnologia, Inovações e Comunicações, com o objetivo definir os critérios para monitoramento dos impactos do Programa.

As Empresas que se habilitarem no Programa terão direito (i) à dedução de até $30 \%$ dos dispêndios com pesquisa e desenvolvimento do valor a ser pago a título de IRPJ e da CSLL; (ii) a dedução adicional de até 15\% sobre os dispêndios com pesquisa e desenvolvimento tecnológico considerados estratégicos, como aqueles relativos à manufatura avançada, conectividade, sistemas estratégicos, soluções para a mobilidade e logística, novas tecnologias de propulsão ou autonomia veicular e suas autopeças, desenvolvimento de ferramental, moldes e modelos, nanotecnologia, pesquisadores exclusivos, big data, sistemas analíticos e preditivos (data analytics) e inteligência artificial; (iii) redução das alíquotas de IPI, a partir de 2022 , de até $2 \%$ para os veículos que atenderem a requisitos específicos de eficiência energética; até $1 \%$ para os veículos que atenderem a requisitos específicos de desempenho estrutural associado a tecnologias assistivas à direção; e até 3\% para os veículos híbridos equipados com motor que utilize, alternativa ou simultaneamente, gasolina e álcool (flexibe fuel engine) em relação aos veículos convencionais, de classe e categoria similares, equipados com o mesmo tipo de motor.

No âmbito do Rota 2030, foi instituído, ainda, o Regime de Peças Não Produzidas, que concede a isenção do Imposto de Importação para aquisição do exterior das partes, peças, componentes, conjuntos e subconjuntos, acabados e semiacabados, e pneumáticos, sem capacidade de produção nacional equivalente. A contrapartida, no caso, é a de que as empresas utilizem os bens importados na industrialização de produtos automotivos no prazo de três anos, e depois realizem no Brasil dispêndios correspondentes ao montante equivalente à aplicação da alíquota de $2 \%$ do valor aduaneiro em projetos de pesquisa, desenvolvimento e 
inovação e em programas prioritários de apoio ao desenvolvimento industrial e tecnológico para o setor automotivo e sua cadeia.

Vê-se, portanto, que o Programa Rota 2030 prevê diversas obrigações aos particulares para que esses posam usufruir dos incentivos fiscais, funcionando como verdadeiras normas indutoras para alcance dos objetivos de modernização da indústria automobilística e adequação às exigências internacionais de sustentabilidade e segurança. O novo marco regulatório está normativamente mais bem apresentado que o do Inovar-Auto, possuindo, inclusive, um planejamento a longo prazo para o alcance das metas, havendo maiores chances de sucesso.

Ademais, no Programa Rota 2030, existe uma viabilidade de se atender a comandos constitucionais, como a defesa do consumidor, em face da preocupação com a segurança dos veículos; da proteção do meio-ambiente (art. 170, VI, da $\mathrm{CR} / 88$ ), devido aos itens de eficiência energética, bem como de desenvolvimento tecnológico (arts. 170, I, 218 e 2019 da CR/88), diante das normas direcionadas ao fomento das pesquisas. Infelizmente, contudo, a busca ao pleno emprego (art. 170, VIII, da CR/88) e outros comandos constitucionais não foram objeto do Programa e de suas normas premiais.

\section{OUtros Incentivos TributáRIOS No SETOR AUtOMOTIVO}

Nas seções anteriores, foi possível constatar que a União frequentemente instituiu um modelo de desenho institucional em favor das empresas do setor automotivo regimes especiais de incentivos fiscais, que preveem o atendimento de contrapartidas a sua concessão. No entanto, o setor é, ainda, agraciado com outros incentivos fiscais extra regimes especiais.

Na história mais recente, vale citar a sequência de uma série de reduções do Imposto sobre Produtos Industrializados, implementadas como política anticíclica em razão dos efeitos da crise financeira mundial de 2008. Para combater os efeitos da crise econômica no Brasil, a União passou a agir indiretamente no domínio econômico de forma mais expressiva, e a redução da alíquota do IPI para os automóveis foi uma das medidas adotadas para amainar a recessão internacional.

A intenção com a desoneração do IPI era de aumentar o consumo dos produtos do mercado interno para preservar o equilíbrio econômico e evitar uma recessão. A primeira redução do IPI teve a duração de mais de um ano e foi instituída por meio da Medida Provisória no 451/08, convertida na Lei no 11.945/2009. Iniciada em dezembro de 2008, a desoneração tinha previsão para acabar em março de 2009, mas foi prorrogada algumas vezes e permaneceu vigente até 31 de março de 2010. A definição dos percentuais das alíquotas estava relacionada à potência do motor, ao tipo de combustível e ao local de produção, se veículo nacional ou importado. De dezembro de 2008 a setembro de 2009 os carros populares, de até mil cilindradas, tiveram o IPI reduzido de $7 \%$ para zero. Os carros com cilindradas 
entre mil e duas mil e movidos à gasolina foram reduzidos de $13 \%$ para 6,5\%, para os biocombustíveis (álcool e gasolina) a alíquota caiu de $11 \%$ para 5,5\%. Contudo, não houve alteração para veículos com mais de duas mil cilindradas e os carros importados tinham as alíquotas do IPI iguais às dos carros nacionais.

A partir de outubro de 2009 as alíquotas foram subindo gradativamente, com maior incentivo para carros bicombustíveis, e em $1^{\circ}$ de abril de 2010 o IPI voltou a ser cobrado integralmente. Todavia, diante do agravamento da crise financeira mundial, agora com maiores efeitos no Brasil, a alíquota dos produtos industrializados foi reduzida pela segunda vez, em maio de 2012, por meio do Decreto $n^{-} 7.725 / 2012$. O benefício deveria ter cessado no final de agosto do mesmo ano, mas foi prorrogado por diversas vezes e encerrou-se ao final de 2013. Nesta segunda redução a diferenciação entre as alíquotas foram relacionadas com a potência do motor, o tipo de combustível e o local de produção.

Diferentemente dos Regimes Especiais estudados anteriormente, as reduções do IPI com o objetivo de aumento do consumo foram concedidas sem a previsão de qualquer contrapartida por parte das Empresas. Informalmente, a contrapartida requerida pelo Governo Federal, era que não houvesse demissões dos empregados pelas montadoras (art. 170, VIII, da CR/88).

O problema da inexistência de contrapartidas prévia e formalmente estabelecidas nesse caso é o fato de que, na hipótese de a redução tributária efetivamente gerar o aumento de vendas, há a possibilidade de se constatar o aumento da margem de lucro das empresas, sem gerar qualquer impacto positivo ao tecido social e a efetivação dos comandos constitucionais.

Ademais, o que se verifica, é que a política econômica brasileira é composta também pela concessão de incentivos fiscais às empresas do ramo automotivo sem qualquer contrapartida, colocando em xeque a sua legitimidade perante a Constituição Econômica.

\section{CONSIDERAÇÕES FINAIS}

Para que os incentivos e benefícios fiscais concedidos pelo Estado às empresas do ramo automotivo, por meio de normas premiais, se adequem à ordem jurídicapolítica-econômica vigente, é necessário o estabelecimento de obrigações também aos particulares. Ou seja, o Estado concede determinado incentivo ao particular que, em contrapartida, deve adotar procedimentos/ações de forma a contribuir para a efetivação da Constituição Econômica e da sua ideologia, fomentando as transformações socioeconômicas, ambientais e tecnológicas fixadas pelos ditames de nossa Lei Maior de 1988.

Verificamos que o desenho institucional das normas concessivas dos incentivos fiscais mais relevantes no Brasil às empresas do setor automobilístico, nos últimos trinta anos, foi dotado de contrapartidas formais aos particulares e geralmente relacionadas às metas a serem alcançadas pelos programas. Em resumo, na época das Câmaras Setoriais, a contrapartida principal era a redução da margem de lucro, 
correção dos salários e manutenção do nível de emprego; no Novo Regime Automotivo, o compromisso de se utilizar de insumos nacionais para a fabricação de veículos; no Inovar-Auto, a realização de maiores investimentos aos setores de pesquisa e desenvolvimento (P\&D), e de inovação tecnológica; e, por fim, no Programa Rota 2030, além de investimentos em P\&D, as contrapartidas das empresas se dão com a redução de emissão de poluentes e segurança veicular.

As exceções ficaram por conta do protocolo de intenções firmado entre a União e as montadoras de veículos em 1993, à margem das Câmaras Setoriais, que não previram qualquer obrigação concreta a ser cumprida pelas empresas em troca da redução à $0,1 \%$ do IPI dos veículos populares; e, ainda, das sucessivas concessões de redução de IPI, no período de 2008 a 2013, com o objetivo de aumentar o consumo dos veículos, induzindo o mercado interno, mas sem qualquer contrapartida formal.

Verificou-se, ademais, que a concessão de renúncias fiscais está normalmente ligada às crises econômicas cíclicas nacionais e/ou internacionais, dificuldades da balança comercial, imposição de força do poder econômico automotivo, e economia de combustíveis, afastando-se, em grande medida, da concretude dos comandos da nossa constituição econômica. Isso porque, ao conceder determinados incentivos, o Estado (União) deixa de estabelecer normativamente aos particulares contrapartidas (reais e verificáveis) objetivando comportamentos ou procedimentos fomentadores da justiça social, valor que compõe a ideologia constitucional adotada, cuja materialização se dá a partir da observância dos comandos da nossa Lei Maior voltados ao pleno emprego (art. 170, inciso VIII, da CR/88), a defesa ao consumidor (art. 170, V, CR/88, a soberania nacional (art. 170, I, da CR/88), a defesa do meio ambiente (art. 170, VI, da CR/88), ao desenvolvimento tecnológico (art. 218 da CR/88).

Em que pese a existência das contrapartidas, pelo menos nos Programas mais extensos estudados (não acontecendo com os outros), o ponto crítico é a constatação da dificuldade de atestar a efetividade das políticas públicas econômicas executadas, ou seja, o alcance das metas estipuladas para o setor automotivo e, consequentemente, atestar a promoção da justiça social, via manutenção ou aumento de empregos, fomento de novos institutos tecnológicos, avanço no processo de industrialização, redução dos índices de poluição, etc. Tal dificuldade fica latente pela inexistência de ações estatais de comprovação dos resultados das normas premais, sendo essas utilizadas, portanto, via instituição de novos regimes tributários diferenciados, fora dos ditames constitucionais e geralmente pelos motivos supracitados.

Todavia, o novo marco regulatório estabelecido pelo Rota 2030 parece fugir ao ciclo vicioso. Trata-se de um programa de longo prazo, divido em ciclos planejados, com métricas mais consistentes vinculadas à emissão de poluentes e segurança 
veicular, condicionando parte dos benefícios fiscais aos investimentos em pesquisa e desenvolvimento de novas tecnologias. Além disso, contará com um monitoramento multidisciplinar, auxiliando na verificação da efetividade do programa.

\section{REFERÊNCIAS}

ANDERSON, Patrícia. Câmaras setoriais: histórico e acordos firmados - 1991/95. Texto para Discussão. IPEA, n. 667, 1999.

ANFAVEA. Estatísticas, 2019. Disponível em:

$<$ http://www.anfavea.com.br/docs/SeriesTemporais_Autoveiculos.xlsm r/estatisticas.html >. Acesso em 10 jan. 2019.

BRASIL. Lei Federal nํ 8.178, de 1ํo de março de 1991, DOU 4 mar. 1991. < http://www.planalto.gov.br/ccivil_03/leis/L8178.htm > Acesso em 12 jan. 2019.

BRASIL. Medida Provisória no 563 de 3 de abril de 2012. DOU 4 abr. 2012.

Disponível em: < http://www.planalto.gov.br/ccivil_03/_Ato2011-

2014/2012/Mpv/563.htm > Acesso em 12 jan. 2019.

BRASIL. Medida Provisória no 843 de 5 de julho de 2018. DOU 6 jul. 2018.

Disponível em: < http://www.planalto.gov.br/ccivil_03/_ato2015-

2018/2018/Mpv/mpv843.htm > Acesso em 12 jan. 2019.

CARNEIRO, Mariana. Gasto com pesquisa na indústria automotiva caiu no Inovar-Auto. Folha de São Paulo. São Paulo, 21 dez. 2017. Mercado. Disponível em: < https://www1.folha.uol.com.br/mercado/2017/12/1945022-gasto-compesquisa-caiu-no-inovar-auto.shtml >. Acesso em: 12 jan. 2019.

CLARK, Giovani. O Município em face do Direito Econômico. Belo Horizonte: Del Rey, 2001.

CLARK, Giovani. Política Econômica e Estado. In: GALUPPO, Marcelo Campos. O Brasil que queremos. Reflexões Sobre o Estado Democrático de Direito. Belo Horizonte: Editora PUCMINAS. 2006. 
CLARK, Giovani; CORRÊA, Leonardo Alves; NASCIMENTO, Samuel Pontes do. Ideologia Constitucional e Pluralismo Produtivo. Revista da Faculdade de Direito da Universidade Federal de Minas Gerais, v. Especial, 2013, p. 265-300.

GODOI, Marciano Seabra de. Finanças Públicas Brasileiras: Diagnóstico e combate dos principais entraves à igualdade social e ao desenvolvimento econômico. Revista de Finanças Públicas, Tributação e Desenvolvimento, v. 5, n. 5, 2017.

GRAU, Eros Roberto. A Ordem Econômica na Constituição de 1988

(Interpretação e Crítica). 16 ed. São Paulo: Malheiros Editores, 2014.

LIMA, Uallace Moreira. O Brasil e a cadeia automobilística: uma avaliação das políticas públicas para maior produtividade e integração internacional entre os anos 1990 e 2014. Texto para Discussão. IPEA, n.․․ 2167, 2016.

MESSA, Alexandre. Impacto de políticas de exigência de conteúdo local: o caso do Programa Inovar-Auto. In: MESSA, Alexandre; Oliveira, Ivan Tiago Machado (Orgs.) A política comercial brasileira em análise. Brasília: Ipea, 2017.

RIATO, Giovana. Resultados do INOVAR-AUTO decepcionam. Automotive Business. Indústria. São Paulo, 09 mar. 2017. Disponível em: $<$ http://automotivebusiness.com.br/noticia/25447/resultados-do-inovar-autodecepcionam >. Acesso em: 12 jan. 2019.

SEM AUTOR. Executivos acreditam que metas no Inovar-Auto não serão atendidas. Revista Auto Esporte. Rio de Janeiro, 10 mar. 2017. Disponível em < https://revistaautoesporte.globo.com/Noticias/noticia/2017/03/executivosacreditam-que-metas-do-inovar-auto-nao-serao-atendidas.html > Acesso em 12 jan. 2019.

SHAPIRO, Mario G. O estado pastor e os incentivos tributários no setor automotivo. Revista de Economia Política, v. 37, n. 2, 2017.

SOUZA, Washington Peluso Albino de. Primeiras Linhas de Direito Econômico. 6 ed. São Paulo: LTr, 2017. 